\title{
Research on the Application of Augmented Reality Technology into the Educational Activities of Kindergarten's Number Concept
}

\author{
Peng Huang*, Xiaoping Yang \\ Faculty of Education, Southwest University, Chongqing, China \\ Email: *1045310231@qq.com
}

How to cite this paper: Huang, P., \& Yang, X. P. (2020). Research on the Application of Augmented Reality Technology into the Educational Activities of Kindergarten's Number Concept. Creative Education, 11, 2722-2729.

https://doi.org/10.4236/ce.2020.1112199

Received: November 23, 2020

Accepted: December 19, 2020

Published: December 22, 2020

Copyright $\odot 2020$ by author(s) and Scientific Research Publishing Inc. This work is licensed under the Creative Commons Attribution International License (CC BY 4.0).

http://creativecommons.org/licenses/by/4.0/

\begin{abstract}
Augmented Reality (AR) is different from virtual reality (VR). It is an emerging technology that does not emphasize the creation of virtual feelings through virtual objects, but focuses on combining virtual objects with real environments. This article starts from the connotation interpretation and characteristic analysis of augmented reality technology, and examines the current kindergarten number concept education activities, and finds that there are the following problems in kindergarten number concept education activities: insufficient creation of mathematics environment, single learning methods for children, and lack of effective learning among children interactive. Combining the characteristics and functions of augmented reality technology, we propose optimization strategies for optimizing kindergarten math concept education activities, respectively creating a unity of "form" and "body" for the environment, rich game experience and dialogue-creating-meaning construction of children's mathematics cognition.
\end{abstract}

\section{Keywords}

Augmented Reality Technology, Concept of Children's Number, Educational Activities

\section{Introduction}

In 2018, the Ministry of Education issued the "Education Informatization 2.0 Action Plan", which clearly stated that "persistence in innovation" should be a basic principle, and proposed to "use technological advantages, change traditional models, and promote new technologies and education." The deep integration of teaching truly realizes the transition from the integration application 
stage to the innovative development stage, not only realizing normalized application, but also achieving all-round innovation. Augmented reality (AR) technology, as one of the most emerging information technologies at the moment, is well used in all fields of society. Relying on its core characteristics of the coexistence of virtual and reality, it can create immersive scenes, thereby realizing deep interaction between humans and the environment. The characteristic toilets of AR technology, such as the combination of virtual and reality, the simultaneous operation of virtual and reality, and the interaction of nature, can create teaching scenarios, enhance students' experience and improve their learning efficiency (Zhao, 2018). Kindergarten teaching activities emphasize the creation of real situations, allowing children to learn independently and cooperate and communicate in them (Yang \& Yang, 2019).

Children's number concept education activities are an important part of kindergarten mathematics education, and a good way of education activities of number concept can greatly promote the formation and development of children's number concept. In the research of Professor Zhou Xin, it is pointed out that the development of children's number concept is a gradual process, an active construction process and dependent on perceptual experience. Mathematics education in the United States emphasizes the cultivation of the ability to use tools. Starting from kindergarten, children use various tools to explore mathematical laws and understand mathematical relationships (Zhou, 2004). The use of tools helps to realize the transition from the real object to the understanding of abstract symbols; the use of tools helps to realize the externalization of the thinking process (Mei, 2014). Wu Fuling designed sports games based on the elements contained in the number concept and related research on the development of children's number concepts. After an 8-week game intervention in the experimental class, she concluded that sports games designed based on the number concept elements promoted children's number concept and development of athletic ability ( $\mathrm{Wu}, 2017)$.

However, augmented reality can fully make children move, learn in sports, and continuously improve their experience of counting concepts in the interaction with the environment. Based on this, the use of augmented reality technology to create a good mathematics learning environment for children and provide diversified and playful learning methods can provide powerful help for the design and implementation of kindergarten math concept education activities. To this end, this research attempts to examine the current problem of the concept of education activities in kindergartens based on the in-depth analysis of the connotation and characteristics of augmented reality technology, and proposes an application strategy for integrating augmented reality technology into the concept education activities of kindergartens, with a view to providing a new era of kindergarten numbers. Concept education activities provide references, so as to give play to the supporting and guiding role of educational informatization for the modernization of preschool education. 


\section{Connotation and Characteristics of Augmented Reality Technology}

\subsection{Explanation of the Connotation of Augmented Reality Technology}

Augmented reality technology is a research hot spot in the field of computer and educational technology. It mainly creates a scene where the virtual and the reality coexist in the real situation to affect the learners or participants' deep knowledge ( $\mathrm{Li}, 2001)$. The combination of virtual and real can be regarded as the biggest feature of augmented reality technology, emphasizing the appearance and dynamic display of virtual objects in real situations. Whether it is a spring scene such as swallows flying, willow branches flying, or peach blossoms, it can virtualize it, allowing learners to immerse in it and feel the atmosphere of spring, so as to realize the physical and mental experience and feelings of learners. The emergence of augmented reality technology as a new type of technology will have a huge impact on kindergarten teaching activities. Of course, it is an expected demand to use it rationally to maximize its value.

\subsection{Characteristic Analysis of Augmented Reality Technology}

Augmented reality technology enhances and strengthens the real world through the combination of the real world and the virtual world, thereby enhancing people's ability to recognize and transform the real world in a new way (Yang, Yang, \& Zhang, 2020). Specifically, it mainly includes the following three characteristics:

\subsubsection{Combination of Virtuality and Reality: Situational Scene}

By integrating the virtual environment with the actual environment, you will not feel the disharmony caused by the fusion of true and false. The creation of a kindergarten mathematics education activity environment can use its technology to create a good mathematics environment. Through the creation of contextualized scenes, children's interest in and attention to math activities will be lengthened, which will effectively promote the development of mathematics education activities.

\subsubsection{Real-Time Interactivity: Dynamic Interaction}

Users can directly interact with virtual objects or virtual environments through interactive devices, which enhances users' perception of the environment. Good interaction is an important factor to promote children's learning. In the mathematical environment created by augmented reality technology, children can further consolidate their mathematical experience acquisition through interaction with the environment and interaction with others.

\subsubsection{Three Dimensions Positioning: Creating Biochemical Games}

Video-based augmented reality system. On the one hand, the video captured by the camera is directly displayed on the display, so that the user can see the real 
scene. On the other hand, the virtual video captured by the virtual camera is sent to the display through the virtual and real cameras. The omni-directional alignment of the virtual and real scenes is integrated, and virtual objects can be added and positioned freely in three-dimensional space. Games are creative, as are math games and number concept games. With the help of the three dimensions positioning function of augmented reality technology, children can further develop creative games after activities, freely locate virtual objects or add new elements, which will promote toddlers engage in in-depth activities of number concepts to realize the formation of number concepts and the continuous growth of experience.

\section{Examination of the Problem of the Educational Activities of the Number Concept in Kindergartens}

Through in-depth interviews with three front-line preschool teachers (see Table 1 for details of survey information) and text analysis of their teaching plans for mathematical concepts, it is known that there are the following problems in kindergarten mathematical concepts education activities.

\subsection{Insufficient Creation of Mathematical Environment}

The creation of a good environment can stimulate children's interest in learning and the continuity of activities. In the communication with kindergarten teachers, it is found that in children's routine math concept activities, teachers often use language or simple objects to create a learning environment. One of the teachers said: "It is difficult to create a mathematical environment. Unlike other fields, especially in the mathematical concept activities, there is no direction at all. Just a few numbers. How to create a learning environment." The concept activity environment is not created enough, and there are even big mistakes. The environment creation of mathematical concept education activities should be integrated into the creation of the entire class environment. In addition, the context creation in mathematical concept activities is also very important.

\subsection{Children's Learning Methods Are Single}

Mathematics is a bit boring compared to other fields. Especially the number concept activities, simple numbers, division and combination, ordinal base number learning is its core experience. In the math concept activity lesson plan designed by the teacher, it is found that kindergarten teachers have strict control over the entire math concept education activity, mainly preaching and simple self-operation, and the game component is relatively lacking. It can be seen that the learning method of children's number concept is relatively simple, which cannot fully activate children's nature, and fails to grasp the characteristics of children's learning to carry out mathematical concept education activities.

\subsection{Children Lack Effective Interaction in Activities}

Effective communication and interaction can promote the growth of children's 
Table 1. Survey information table.

\begin{tabular}{|c|c|c|c|c|}
\hline Kindergarten & Attributes & $\begin{array}{l}\text { Teachers and their } \\
\text { professional titles }\end{array}$ & Research time & The main methods and content of the survey \\
\hline J kindergarten & City Level One Park & $\begin{array}{l}\text { J1 (Advanced), } \\
\text { J2 (Intermediate) }\end{array}$ & April 10, 2020 & $\begin{array}{l}\text { Depth interviews: } \\
\text { 1) The significance of mathematics teaching }\end{array}$ \\
\hline F kindergarten & City Level One Park & $\begin{array}{l}\text { F1 (Advanced), } \\
\text { F2 (Intermediate) }\end{array}$ & June 9, 2020 & $\begin{array}{l}\text { 2) The value of mathematics teaching } \\
\text { 3) The purpose of mathematics teaching } \\
\text { 4) The content of mathematics teaching }\end{array}$ \\
\hline S kindergarten & City Level One Park & $\begin{array}{l}\text { S1 (Advanced), } \\
\text { S2 (Intermediate) }\end{array}$ & October 30, 2020 & $\begin{array}{l}\text { 5) Methods of mathematics teaching } \\
\text { 6) Factors affecting mathematics teaching } \\
\text { 7) Experience and suggestions of mathematics teaching }\end{array}$ \\
\hline
\end{tabular}

concept of number experience. In the interview with the teacher, it was found that the teacher had a relatively shallow understanding of the interaction between children in the mathematical concept activities, thinking that a simple dialogue or response was to achieve a deep dialogue and communication between children. For example, in the " 5 's Divide and Combine" activity, the teacher asks children to answer each other decomposition of 5 and match them in a game, which is a good interaction. Interaction should be a process of meaning generation and construction, not a simple formality. Games are needed, but not for the sake of games. It is necessary to understand the relationship between games and teaching. Therefore, effective interaction is currently lacking in children's mathematical concept learning.

\section{Strategies for Integrating Augmented Reality Technology into Kindergarten Education Activities of Number Concept}

\subsection{The Unity of "Form" and "Body" Created by the Environment}

Montessori once said, "In a prepared environment, young children can teach themselves." It can be seen that the importance of environmental creation to kindergarten education is self-evident. The "shape" of environment creation mainly emphasizes that mathematics education should be integrated into the creation of kindergarten's theme wall and class corner environment, so that children can perceive the fun of mathematics in daily life. The "body" created by the environment mainly emphasizes that in the real mathematical concept learning activities, the augmented reality technology combines virtual and real to provide an effective language environment and visual environment for the kindergarten mathematical concept education activities, so that children can develop and develop in the real scene. Form the concept of number (Yan, Chen, \& Xu, 2019).

\subsection{Rich Gaming Experience}

It has become the educational creed of every kindergarten worker to use games as a basic activity in kindergartens, and we need to carefully understand and reflect it in the daily life of kindergarten. Mathematics education is relatively boring due to its own characteristics. However, with the help of augmented reality 
technology to create a vivid and immersive learning environment, children can perceive mathematics embodiedly, and by setting game challenges with different levels of difficulty, such as through games, let children perceive the fun of mathematics in the operating experience. Promote the formation and development of children's number concept.

\subsection{Dialogue-Creation-Meaning Construction of Children's Cognition}

Human-computer interaction can create a curriculum culture of interaction and meaning construction ( $\mathrm{Li}, 2019)$. In math concept education activities, relying on augmented reality technology, create interaction and sharing to realize the meaning construction of mathematics concepts for children in activities, which will fundamentally realize the improvement of children's mathematical experience. In addition, children create their own understanding and cognitive experience of number concepts in embodied situations. For example, in the "Five Divisions" (specific activities shown in Table 2 below), children are helped to perceive the change relationship between numbers and quantities through gamification, so as to better grasp the basic mathematical concepts such as numbers

Table 2. “5’s Division” activity process.

\begin{tabular}{lll}
\hline Activity Steps & Activity Key Points & Tips \\
\hline & ODirect import & $\star$ Teachers encourage guessing and \\
& $\begin{array}{l}\text { First, review the composition of numbers } 3 \text { and } 4 \text { to realize the transfer of children's } \\
\text { experience; secondly, put forward the main content of today's activity, encourage children }\end{array}$ & $\begin{array}{l}\text { provide relevant materials to help } \\
\text { children record the guessing process. }\end{array}$ \\
& to guess the division and combination of number 5 and make their own exploration & \\
Event import & statistics.
\end{tabular}

\section{ODesign intent}

This link is mainly to realize the connection and transition of children's original mathematics experience and activity experience, and prepare for the activity through recounting, guessing and other links.

OInquiry activities-separation, separation and combination (reflecting the separation $\star$ Teachers make full use of various and combination of 5) materials to make the explanation First, the teacher asks questions and collects the children's guess results: children, how can process gamified and life-like. For the number 5 be split and combined, and show the teacher your thoughts; second, go back example, if you want to buy 5 apples, to the 5 with the children to clarify and consolidate the three numbers Divide and combine you already have three apples, how experience. many apples can you still get?

Teacher: It turns out that when the digital baby gets bigger and bigger, it can have more combinations of division methods. In the process of splitting and combining, the number

Activity development as a whole is smaller than the digital baby, but the situation of splitting and combining may be large or small, sometimes Will be very close to it again. When we wrote down the division and integration, the kids, what did you find?

\section{O AR game-divide, divide, combine}

First of all, teachers guide: children, more and more friends come to our birthday party, come and prepare food for the guests and children! How to put so much food on two plates, and how many ways to distribute it? Secondly, teachers demonstrate movements to help children master the essentials of movements.

Teacher: It turns out that a quantity of food can have different distribution methods. A number can be composed of different numbers. The total number of points, points, and points is still the same, which is amazing. $\star$ The teacher demonstrates to help children master the basic movement essentials: Raise the left or right hand to separate objects, move left and right and then jump to choose the correct option. 


\section{Continued}

1) Refined mathematical experience related to the division and integration of numbers from game experience, such as the increase and decrease of numbers in the process of

Activity ends division and integration;

2) Summarize the game process, especially the process of logical reasoning from the split-and-close game, to help clarify how to reason and how to solve the problem. $\star$ The experience summaries are combined with the children's play process to make it intuitive and concrete.

$\star$ Teachers pay attention to the

1) Painting area: try to create your own storybook with figures as the theme content;

2) Reading and writing area: Try to copy numbers and provide materials for children to try completeness and logic of children's to count the specific situations of separation and integration.
Activity

extension and quantitative relations. This activity adopts birthday party scenes close to children's lives, infiltrates five points of experience through relevant game links, and promotes the development of children's mathematics and logic through children's meaning construction and interactive sharing.

All in all, with the help of AR technology to design kindergarten number concept education activities, children can learn independently and cooperative games in them. Augmented reality technology has important value in kindergarten math activities, which is reflected in the interaction between the individual and the environment, the integration of reality and virtuality, the closeness of time and space, and the collaboration between ourselves and others; augmented reality technology is used in kindergarten math activities The application of augmented reality teaching, augmented reality learning game environment and augmented reality laboratory programs promoted the deep integration of science and technology and kindergarten math activities, and provided strong support for the improvement of the quality of kindergarten math education and the development of children's number concepts. However, the issue worthy of further discussion is how to measure and evaluate the development of the concept of children's number in order to reflect the absolute value of the application of augmented reality technology, which will become the focus of researchers' follow-up study and research.

\section{Conflicts of Interest}

The authors declare no conflicts of interest regarding the publication of this paper.

\section{References}

Li, F. (2019). Discussion on the Application of AR Technology in the Field of Early Childhood Education Publishing-Based on the Research of AR Product Development in "Digital Resources for Innovative Activity Courses for Children". Information and Computer (Theoretical Edition), 250-253.

Li, K. D. (2001). Digital Learning (on) the Core of Information Technology and Curriculum Integration. Audio-Visual Education Research, 8.

Mei, Y. (2014). The Curriculum Design Characteristics and Enlightenment of "Number Concept" in American Kindergartens-Based on the Comprehensive Analysis of Preschool Books and Teachers'Books. Wuhan: Huazhong Normal University, 38-42. 
Wu, F. L. (2017). Research on Sports Games to Promote the Development of Children's Concept of Number in Middle Class. Shanghai: Shanghai Normal University, 22-25.

Yan, F. Q., Chen, Y. P., \& Xu, X. Q. (2019). Research on Educational Activities Strategies for the Concept of Numbers in Kindergartens under the New Curriculum Concept. Educational Observation, 48-49.

Yang, T., \& Yang, X. P. (2019). Application of Augmented Reality Technology in Kindergarten Teaching: Value Logic and Action Strategy. Journal of Shaanxi Preschool Teachers College, 22-27.

Yang, X., Yang, X. P., \& Zhang, Q. (2020). The Connotation Value and Practice Path of the Integration of AR Technology and Kindergarten Curriculum. Preschool Education Research, 89-92.

Zhao, H. D. (2018). The Application Value and Implementation Strategies of AR Technology in Modern Teaching. Contemporary Education Review (Seventh Series), Jinan: Shandong Normal University.

Zhou, X. (2004). Early Development of Children's Number Concept. Shanghai: East China Normal University Press, 11-20. 